\title{
EH-myomesin splice isoform is a novel marker for dilated cardiomyopathy
}

\author{
Roman Schoenauer • Maximilian Y. Emmert • Allison Felley • Elisabeth Ehler • \\ Chad Brokopp • Benedikt Weber • Mohamed Nemir · Giuseppe G. Faggian • \\ Thierry Pedrazzini $\cdot$ Volkmar Falk • Simon P. Hoerstrup • Irina Agarkova
}

Received: 7 July 2010/Revised: 29 September 2010/Accepted: 25 October 2010/Published online: 11 November 2010

(C) The Author(s) 2010. This article is published with open access at Springerlink.com

\begin{abstract}
The M-band is the prominent cytoskeletal structure that cross-links the myosin and titin filaments in the middle of the sarcomere. To investigate M-band alterations in heart disease, we analyzed the expression of its main components, proteins of the myomesin family, in mouse and human cardiomyopathy. Cardiac function was assessed by echocardiography and compared to the expression pattern of myomesins evaluated with RT-PCR, Western blot, and immunofluorescent analysis. Disease progression in transgenic mouse models for dilated cardiomyopathy (DCM) was accompanied by specific M-band alterations. The dominant splice isoform in the embryonic heart, EH-myomesin, was strongly up-regulated in the failing heart and correlated with a decrease in cardiac function $(R=-0.86)$. In addition, we have analyzed the expressions of myomesins in human myocardial biopsies
\end{abstract}

S. P. Hoerstrup and I. Agarkova contributed equally to this work.

Electronic supplementary material The online version of this article (doi:10.1007/s00395-010-0131-2) contains supplementary material, which is available to authorized users.

R. Schoenauer · M. Y. Emmert · C. Brokopp · B. Weber ·

S. P. Hoerstrup · I. Agarkova

Swiss Center for Regenerative Medicine, University of Zurich,

Zurich, Switzerland

R. Schoenauer · M. Y. Emmert - C. Brokopp · B. Weber ·

S. P. Hoerstrup - I. Agarkova $(\square)$

Department of Surgical Research, University Hospital Zurich,

Rämistrasse 100, 8091 Zurich, Switzerland

e-mail: irina.agarkova@usz.ch

M. Y. Emmert - B. Weber · V. Falk · S. P. Hoerstrup .

I. Agarkova

Clinic for Cardiovascular Surgery, University Hospital Zurich,

Zurich, Switzerland
$(N=40)$ obtained from DCM patients, DCM patients supported by a left ventricular assist device (LVAD), hypertrophic cardiomyopathy (HCM) patients and controls. Quantitative RT-PCR revealed that the EH-myomesin isoform was up-regulated 41 -fold $(P<0.001)$ in the DCM patients compared to control patients. In DCM hearts supported by a LVAD and HCM hearts, the EH-myomesin expression was comparable to controls. Immunofluorescent analyses indicate that EH-myomesin was enhanced in a cell-specific manner, leading to a higher heterogeneity of the myocytes' cytoskeleton through the myocardial wall. We suggest that the up-regulation of EH-myomesin denotes an adaptive remodeling of the sarcomere cytoskeleton in the dilated heart and might serve as a marker for DCM in mouse and human myocardium.

Keywords Dilated cardiomyopathy · Heart failure · Sarcomere cytoskeleton $\cdot$ M-band $\cdot$ Myomesin

\author{
A. Felley $\cdot$ M. Nemir $\cdot$ T. Pedrazzini \\ Department of Medicine, University of Lausanne Medical \\ School, Lausanne, Switzerland \\ E. Ehler \\ The Randall Division of Cell and Molecular Biophysics and the \\ Cardiovascular Division, King's College London, London, UK \\ G. G. Faggian \\ Division of Cardiac Surgery and Cardiology, \\ University of Verona, Verona, Italy
}


Fig. 1 Sarcomere cytoskeleton and M-band protein components. a Scheme of the sarcomere depicting the main components of the sarcomeric cytoskeleton (M-band, Z-disk and titin). b Myomesin (white), M-protein (gray) and myomesin-3 (dark gray) are composed of immunoglobulinlike domains (ellipses) and fibronectin type 3 domains (rectangles). The alternatively spliced EH-domain (EH) and the N-terminal domains are intrinsically unstructured
A
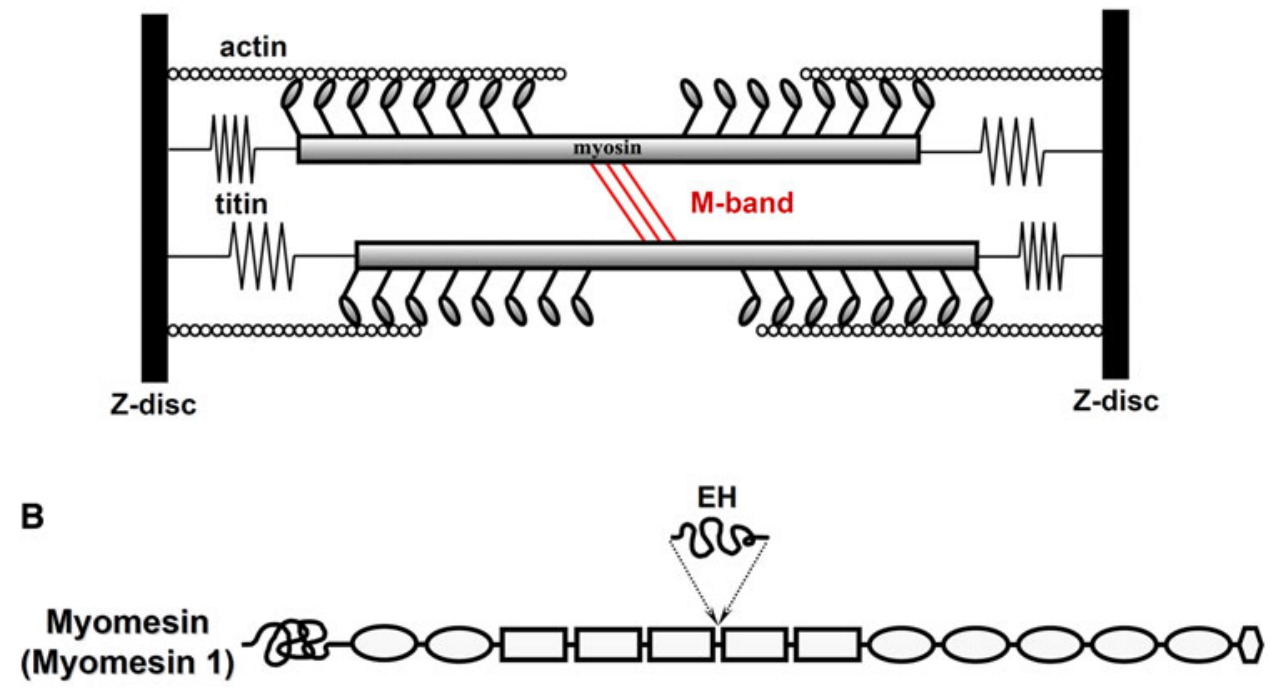

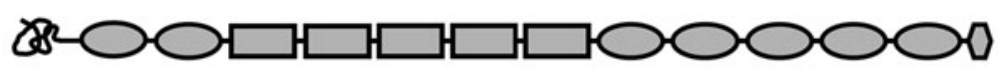

M-protein
(Myomesin 2)

Myomesin 3

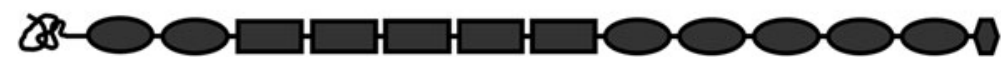

\section{Introduction}

Dilated cardiomyopathy (DCM), is a major and increasing cause of morbidity and mortality including sudden cardiac death, and affects approximately 40 out of 100,000 people, of which $30-50 \%$ have a genetic origin [20]. Characterized by left ventricular dilation and systolic dysfunction, DCM often leads to terminal heart failure requiring cardiac transplantation [13]. Most identified mutations affect genes encoding cytoskeletal proteins suggesting the impairment of force transmission [28] or failing of the cardiomyocyte stretch sensor machinery [22] as possible mechanisms underlying this disorder. However, also the mutations in sarcomeric proteins [20] and nuclear membrane protein lamin A/C encoding genes [17, 32] may cause DCM. In addition, there is growing evidence that acquired factors such as autoimmunity, virus-induced chronic inflammation and impaired protein quality control may also contribute to the DCM development and heart failure [21, 38]. While the cause of the disease might be identified in many cases, the pathophysiological mechanisms that control the progression to the irreversible ventricular remodeling and heart failure are largely unknown [14]. The analysis of sarcomeric cytoskeleton alterations, in particular of the M-band, might provide important clues to understand the pathological mechanisms in DCM.

The basic functional unit of the heart muscle is the sarcomere, which contracts due to sliding of myosin over actin filaments. The sarcomere cytoskeleton provides the scaffold for contractile filaments and includes three basic structural elements: the Z-disk and the M-band, two transverse structures anchoring the thin and thick filaments, and the elastic titin filaments connecting these longitudinally (Fig. 1a). The M-band is believed to organize the thick filament lattice and plays an important role in sarcomere mechanics [3]. Its important structural elements are three closely related proteins of the myomesin family (Fig. 1b). Myomesin (or myomesin-1) [16] appears to be an essential component of the sarcomere as it was found in all studied vertebrate muscles. Myomesin makes anti-parallel dimers which are believed to cross-link the myosin filaments in the M-band, a role analogous to $\alpha$-actinin in the Z-disk [23]. Myomesin interaction with the titin M-band portion [30] might be crucial for the mechano-sensing and signaling functions mediated by the stretch-activated Ser/Thr-kinase domain of titin [3, 24, 34]. Myomasp/ LRRC39 was characterized recently as a novel M-band component associated with mechano-sensitive signaling pathways [40]. Interestingly, the knockdown of myomasp leads to a significant down-regulation of myomesin- 1 and myomesin-2 expression and decreases contractile force in heart muscle. The EH-myomesin splice isoform (see Fig. 1b), generated by inclusion of an elastic segment [35] in the center of the molecule, is the main M-band component in the embryonic heart of higher vertebrates [1] and is expressed in slow skeletal fibers of mice [4]. Similarly, two other members of the myomesin protein family, M-protein and myomesin-3, show muscle-type specific 
expression patterns. M-protein is found in adult heart and fast skeletal muscle [15], myomesin-3 appears in intermediate speed fibers of skeletal muscle but not in mouse heart at any developmental stage [36]. This indicates that the M-band is a dynamic structure which adapts to the contractile parameters of a given muscle by varying the proportion of EH-myomesin and the level of M-protein and myomesin-3. Accordingly, this cytoskeletal system might represent a valid biomarker for pathological processes in the heart such as cardiomyopathy.

Aiming to establish the general relationships between the M-band alterations and heart function, we have designed a study comprising the analysis of mouse models and human myocardial biopsies. We first studied the M-band protein alterations in the hearts of two transgenic mouse models: the muscle LIM protein knockout mouse (MLP-KO), a wellestablished model for DCM [5] and a mouse with stabilized $\beta$-catenin in the heart ( $\beta$-catenin $\Delta$ ex 3 ), which progressively develops a severe DCM phenotype resulting in heart failure and premature death [19]. The disease progression was monitored by echocardiography and compared to the expression of myomesins. Human samples obtained from cardiac surgery patients were analyzed in the same way.

\section{Methods}

Animal breeding and maintenance

Transgenic knock-in mice expressing Cre recombinase under control of the myosin light chain $2 \mathrm{v}$ promoter [9] were bred with $\beta$-catenin exon 3 floxed mice [18] to generate animals with a stabilization of the protein restricted to the ventricular myocardium (MLC2 $2{ }^{\mathrm{Cre} / \mathrm{wt}} ; \beta$-catenin exon $3^{\text {flox/flox }}$ ) referred to later as $\beta$-catenin $\mathrm{c} \Delta \mathrm{ex} 3$. Genotyping for Cre and $\beta$-catenin alleles was performed as described [25]. MLP-deficient mice were described earlier [5]. Agematched WT controls were used for all experiments. Maintenance and animal experimentation are conforming to the Swiss Federal Veterinary Office guidelines.

\section{Echocardiography}

Transthoracic echocardiography was performed by a blinded investigator using a $30-\mathrm{MHz}$ probe and the Vevo 770 Ultrasound machine (VisualSonics). The rodent was placed under $1 \%$ isoflurane anesthesia via a nose cone and positioned on a $37^{\circ} \mathrm{C}$ heated surface. The eyes of the animals were protected from drying by lubricating ophthalmic gel. Under anesthesia, the following parameters were monitored: heart rate, body temperature (with rectal probe), ECG trace, and respiration. The hair was removed with an epilatory cream (deemed suitable for use in rodents).
The echocardiography images were obtained by placing warmed gel on the rodent, and the ultrasound probe actually never touched the animal itself due to the gel interface. The average anesthetic period lasted $10 \mathrm{~min}$.

Echocardiographic analysis (all measured after the mouse was anesthetized) included basic left ventricular function parameters, cardiac output, stroke volume, left ventricular dimensions, and transvalvular flow indices. The study protocol was approved by the Swiss Federal Veterinary Office.

\section{Antibodies}

Monoclonal mouse anti-myomesin antibodies (clone B4) [16], polyclonal rabbit anti-EH-myomesin (pR-anti-moEH for mouse) [4] and anti-myomesin-3 antibodies (pR-antiMy3-N) [36] were generated as described. The antibodies against human EH-myomesin (pR-anti-huEH) were generated in our laboratory (see details below). Monoclonal mouse anti-M-protein antibodies (clone AA259, IgA) were generously donated by Prof. D. O. Fürst (Potsdam, Germany). Monoclonal antibodies against sarcomeric $\alpha$-actinin (clone EA-53) and polyclonal antibodies against all actin isoforms (A2066) were obtained from SigmaAldrich (Buchs, Switzerland). Monoclonal antibodies against $\beta$-catenin were obtained from Transduction Lab (cat.no. 610154) and antibodies against $\mathrm{N}$-cadherin from Invitrogen (Zymed, 33-3900). Polyclonal antibodies against $\beta$-catenin were obtained from Sigma-Aldrich (C2206) and used for immunoblotting.

Horseradish peroxidase-conjugated anti-rabbit Igs (Calbiochem, San Diego, USA) and anti-mouse IgA (SigmaAldrich) were used as secondary antibodies for immunoblotting. Fluorescein isothiocyanate (FITC)-conjugated goat-anti-mouse IgA (Sigma-Aldrich), Cy3-conjugated goat-anti-mouse IgG (Fab-fragments) and Cy5-conjugated goat-anti-rabbit antibodies were used as secondary antibodies for immunofluorescence staining (Jackson Immuno Research, West Grove, PA, USA).

Generation of antibodies against human EH-myomesin

Total RNA of human embryonic heart was isolated using the SV Total RNA isolation system (Promega, Wallisellen, Switzerland). The EH-fragment of human myomesin was amplified by RT-PCR on approximately $1 \mu \mathrm{g}$ of total RNA with the Access RT-PCR system (Promega) using a standard RT-PCR protocol suggested by the manufacturer. Primers used for the amplification were derived from the human myomesin sequence (see "RT-qPCR"). The segment was cloned into BamHI and EcoRI sites of the bacterial expression plasmid pGEX-2T (Amersham Pharmacia Biotech, Otelfingen, Switzerland) and expressed in the 
E. coli strain BL-21 Star (Invitrogen, Basel, Switzerland). The soluble glutathione $S$-transferase fusion protein was purified from crude bacterial lysate by affinity chromatography on glutathione-agarose (Sigma). Antibodies against human EH-myomesin (anti-huEH) were generated by immunizing adult rabbits with this recombinant EHfragment fused to glutathione $S$-transferase.

\section{SDS-PAGE and immunoblotting}

The procedure was performed as described [36]. Comparable tissue samples of the apex of the heart have been used for protein extraction. Quantification of the signal strength was done by a phosphor-imager (LAS-3000, Fujifilm).

\section{Immunostainings}

The procedure was performed as described [36]. Comparable sections from the lateral wall of the heart have been used for immunostainings.

\section{Confocal microscopy}

Analysis of the stained sections was carried out using a Leica (Leica Microsystems AG, Heerbrugg, Switzerland) confocal unit (Leica SP 5) equipped with an inverse microscope. DAPI was excited by a diode laser with 405 $\mathrm{nm}$ excitation, FITC fluorochrome was excited by an argon laser and $\mathrm{Cy}-3$ and $\mathrm{Cy}-5$ fluorochromes were excited by helium-neon lasers. Leica PL APO 63x/1.32 NA oil or PL APO 10x/0.3 NA oil immersion objectives were used. Image processing was done on a PC workstation using the image processing software Imaris (Bitplane AG, Zurich, Switzerland) and Photoshop (Adobe Systems, San Jose, USA).

\section{RT-qPCR}

Total RNA was isolated from comparable tissue samples of mouse or human tissues using TRIZOL Reagent (Invitrogen AG, Basel, Switzerland) or the RNeasy kit (Qiagen AG, Hombrechtikon, Switzerland). Reverse transcription was carried out on approximately $1 \mu \mathrm{g}$ total RNA, cDNA was produced with the Thermoscript RT-PCR System (Invitrogen, Basel, Switzerland) and amplified using TAQ-polymerase (BioTherm DNA Polymerase; GeneCraft GmbH, Lüdinghausen, Germany). qPCR was performed using iTaq SYBR Green Supermix from Bio-Rad (Reinach, Switzerland) and a LightCycler ${ }^{\circledR} 480$ from Roche (Basel, Switzerland). Relative quantification of RNA levels was calculated by the $\Delta \Delta$ ct method [33]. Primers used for the amplification of the fragments of mouse or human myomesin, M-protein and myomesin-3 were derived from the corresponding sequences [myomesin: Ensembl gene Myom1, ENSMUS G00000024049 (mouse), ENSG00000101605 (human); M-protein: Ensembl gene Myom2, ID ENSMUSG000 00031461 (mouse), ENSG00000036448 (human); myomesin-3: Ensembl gene Myom3, ENSMUSG00000037139 (mouse), ENSG00000142661 (human)]. Sarcomeric alphaactinin: Ensembl gene Actn2 ENSMUSG00000052374 (mouse) and ENSG00000077522 (human) and beta-actin: Ensembl gene Actb, ENSG00000075624 (human) have been used for normalization. For primer sequences, see Supplementary Table S1.

Human samples and patient demographics

The study was approved by an institutional ethics committee and has been performed in accordance with the ethical standards laid down in the 1964 Declaration of Helsinki. Informed consent has been obtained from all patients included in this study. 40 tissue samples (ventricular and atrial) were obtained from 25 patients (16 male, 9 female) who underwent heart surgery. Patients were Caucasians, aged 30-62 years (plus a 0.5-year-old baby) and suffered from idiopathic (with unknown etiology) DCM $(N=13)$ or served as controls $(N=12)$. Control samples (non-dilated) were obtained from patients with hypertrophic cardiomyopathy $(\mathrm{HCM})(N=7)$ or from patients who either underwent adult cardiac surgery $(N=3)$ or congenital heart surgery $(N=2)$. Heart biopsies were obtained from two groups of DCM patients. The first group was classified as end-stage heart-failure (NYHA III-IV) and underwent only heart transplantation $[N=10$, $\mathrm{EF}=12.7 \pm 1.9 \%]$, while the second group was supported by a left ventricular assist device (LVAD) for a certain period of time before heart transplantation $(N=3)$. All samples were processed in liquid nitrogen immediately after harvesting.

Patients in the control group received the standard medication such as aspirin, statins and beta-blockers. In addition, patients who have had valve replacement or repair received warfarin either lifelong or for a certain period of time. Patients who underwent congenital heart surgery mainly did not take any relevant medications. In contrast to this, HCM and DCM patients being in heart failure received standard heart failure medication including ACE inhibitors, beta-blockers, calcium channel inhibitors as well as diuretics.

\section{Statistics}

All data were considered as normally distributed and analyzed by unpaired, two-tailed Student's $t$ test and for multiple comparisons, by one-way or two-way ANOVA. 
Table 1 Echocardiography data (5 weeks)

\begin{tabular}{|c|c|c|c|}
\hline & Wild type $(N=6)$ & $\beta$-Catenin $\mathrm{c} \Delta \operatorname{ex} 3(N=6)$ & MLP-KO $(N=6)$ \\
\hline Age (days) & $35 \pm 0$ & $35 \pm 0$ & $35 \pm 0$ \\
\hline Female/male ratio & $4 / 2$ & $3 / 3$ & $3 / 3$ \\
\hline Body weight $(\mathrm{g})$ & $15.5 \pm 2.9$ & $15.6 \pm 2.8$ & $14.3 \pm 1.3$ \\
\hline Heart rate (beats/min) & $394 \pm 46$ & $372 \pm 42$ & $413 \pm 29$ \\
\hline LVPW;d (mm) & $0.58 \pm 0.03$ & $0.72 \pm 0.08 *$ & $0.72 \pm 0.06^{*}$ \\
\hline LVPW;s (mm) & $0.78 \pm 0.04$ & $0.87 \pm 0.10^{*}$ & $0.83 \pm 0.05$ \\
\hline IVS;s (mm) & $0.78 \pm 0.03$ & $0.79 \pm 0.08$ & $0.83 \pm 0.06$ \\
\hline LVID;d (mm) & $3.39 \pm 0.37$ & $3.75 \pm 0.42$ & $3.90 \pm 0.11^{*}$ \\
\hline LVID;s (mm) & $2.31 \pm 0.29$ & $2.79 \pm 0.49^{*}$ & $2.99 \pm 0.10^{*}$ \\
\hline LV Vol;d $(\mu \mathrm{l})$ & $47.6 \pm 12.4$ & $60.8 \pm 15.1$ & $65.8 \pm 4.7^{*}$ \\
\hline LV Vol;s $(\mu \mathrm{l})$ & $18.6 \pm 5.6$ & $30.5 \pm 12.3$ & $34.6 \pm 2.9^{*}$ \\
\hline $\mathrm{EF}(\%)$ & $61.2 \pm 3.0$ & $51.5 \pm 9.2 *$ & $47.3 \pm 3.0^{*}$ \\
\hline FS $(\%)$ & $31.9 \pm 2.0$ & $26.0 \pm 5.5^{*}$ & $23.4 \pm 1.8^{*}$ \\
\hline Ejection time (s) & $57.3 \pm 4.6$ & $54.6 \pm 4.5$ & $53.0 \pm 3.1$ \\
\hline MV E/A & $1.79 \pm 0.36$ & $2.23 \pm 1.10$ & $1.69 \pm 0.54$ \\
\hline Mean $\mathrm{VcFc}(\mathrm{circ} / \mathrm{s})$ & $0.56 \pm 0.05$ & $0.48 \pm 0.12$ & $0.44 \pm 0.06^{*}$ \\
\hline LV mass (mg) & $47.4 \pm 8.7$ & $69.7 \pm 18.4^{*}$ & $74.9 \pm 5.6^{*}$ \\
\hline LV mass/body weight $(\mathrm{mg} / \mathrm{g})$ & $3.06 \pm 0.37$ & $4.47 \pm 1.18^{*}$ & $5.24 \pm 0.39 *$ \\
\hline
\end{tabular}

Cardiac function and ventricular dimensions of 5-week-old $\beta$-catenin $\mathrm{c} \Delta \mathrm{ex} 3$ and MLP-KO mice assessed by transthoracic echocardiography $L V P W$ left ventricular free wall, IVS interventricular septum, $L V I D$ left ventricular internal diameter, $F S$ fractional shortening, $M V E / A$ mitral valve E:A velocity ratio, $V c F c$ circumferential fiber shortening, $d$ diastole, $s$ systole

* Significant differences compared to wild type

Table 2 Echocardiography data (4 months)

\begin{tabular}{llll}
\hline & Wild type $(N=9)$ & $\beta$-Catenin c $\Delta$ ex3 $(N=9)$ & MLP-KO $(N=6)$ \\
\hline Age (days) & $124 \pm 5$ & $125 \pm 5$ & $139 \pm 4$ \\
Female/male ratio & $4 / 5$ & $6 / 3$ & $4 / 2$ \\
Body weight $(\mathrm{g})$ & $28.1 \pm 3.5$ & $24.2 \pm 2.9^{*}$ & $24.9 \pm 2.0$ \\
Heart rate (beats/min) & $397 \pm 34$ & $421 \pm 52$ & $360 \pm 25$ \\
LVPW;d (mm) & $0.73 \pm 0.07$ & $0.76 \pm 0.09$ & $0.71 \pm 0.04$ \\
LVPW;s (mm) & $0.98 \pm 0.07$ & $0.85 \pm 0.10^{*}$ & $0.86 \pm 0.11^{*}$ \\
IVS;s (mm) & $0.89 \pm 0.03$ & $0.88 \pm 0.07$ & $0.79 \pm 0.03^{*}$ \\
LVID;d (mm) & $4.09 \pm 0.11$ & $5.07 \pm 0.64^{*}$ & $4.64 \pm 0.18^{*}$ \\
LVID;s $(\mathrm{mm})$ & $2.86 \pm 0.11$ & $4.33 \pm 0.73^{*}$ & $3.69 \pm 0.24^{*}$ \\
LV Vol;d $(\mu \mathrm{l})$ & $73.9 \pm 4.5$ & $124.7 \pm 34.9^{*}$ & $99.5 \pm 9.2^{*}$ \\
LV Vol;s $(\mu \mathrm{l})$ & $31.0 \pm 2.9$ & $87.5 \pm 32.2^{*}$ & $58.1 \pm 8.8^{*}$ \\
EF (\%) & $58.02 \pm 3.32$ & $31.65 \pm 8.23^{*}$ & $41.66 \pm 6.5^{*}$ \\
FS (\%) & $30.3 \pm 2.3$ & $15.1 \pm 4.2^{*}$ & $20.5 \pm 3.7 *$ \\
Ejection time (s) & $54.9 \pm 2.9$ & $47.4 \pm 4.5^{*}$ & $54.2 \pm 2.9$ \\
MV E/A & $1.94 \pm 0.62$ & $4.84 \pm 3.37^{*}$ & $4.01 \pm 1.43^{*}$ \\
Mean VcFc (circ/s) & $0.55 \pm 0.05$ & $0.31 \pm 0.06^{*}$ & $0.38 \pm 0.08^{*}$ \\
LV mass (mg) & $81.5 \pm 8.0$ & $134.5 \pm 40.1^{*}$ & $97.2 \pm 9.3^{*}$ \\
LV mass/body weight $(\mathrm{mg} / \mathrm{g})$ & $2.92 \pm 0.29$ & $5.62 \pm 1.75^{*}$ & $3.91 \pm 0.36^{*}$
\end{tabular}

Cardiac function and ventricular dimensions of 4-month-old $\beta$-catenin c $\Delta$ ex3 and MLP-KO mice assessed by transthoracic echocardiography $L V P W$ left ventricular free wall, IVS interventricular septum, $L V I D$ left ventricular internal diameter, $F S$ fractional shortening, $M V E / A$ mitral valve E:A velocity ratio, $V c F c$ circumferential fiber shortening, $d$ diastole, $s$ systole

* Significant differences compared to wild type 
Differences were considered as statistically significant for $P<0.05$.

\section{Results}

Characterization of disease progression in transgenic mouse models for DCM by echocardiography

To evaluate the expression level of the myomesin genes in pathological situations in general, heart samples of mouse models for HCM or DCM were examined by RT-PCR analysis (Figure S1, supplementary material). These experiments showed that alterations in M-band composition are a hallmark of DCM compared to HCM models or controls.

Motivated by this finding, we analyzed the disease progression in detail, using two transgenic mouse models which progressively develop a severe DCM: the MLP-KO mouse [5] and a mouse with stabilized $\beta$-catenin in the heart ( $\beta$-catenin $\mathrm{c} \Delta \mathrm{ex} 3$ ) [19]. Several parameters describing the pump function and dimensions of the heart were measured at the age of 2 weeks, 5 weeks (Table 1), 2 months and 4 months (Table 2) in both mouse models and controls. The diastolic volume of the left ventricle (LV) was clearly enlarged in both models at the age of 4 months verifying the DCM phenotype (Fig. 2a). The hearts of MLP-KO and $\beta$-catenin $\mathrm{c} \Delta \mathrm{ex} 3$ mice showed a significant reduction of the ejection fraction (EF) already at the age of 5 weeks which was even more pronounced at a higher age (Fig. 2b), demonstrating a continuous deterioration of cardiac function during disease progression. Both mouse models have chamber dilation with reduced wall motion, which was more pronounced in the $\beta$-catenin $\mathrm{c} \Delta \mathrm{ex} 3$ mice at the age of 4 months (Fig. 2c).

Alterations in expression of myomesin proteins during the development of DCM

To investigate whether alterations in the protein composition of the sarcomeric M-band can be used as biomarker for processes occurring in diseased heart, we analyzed the
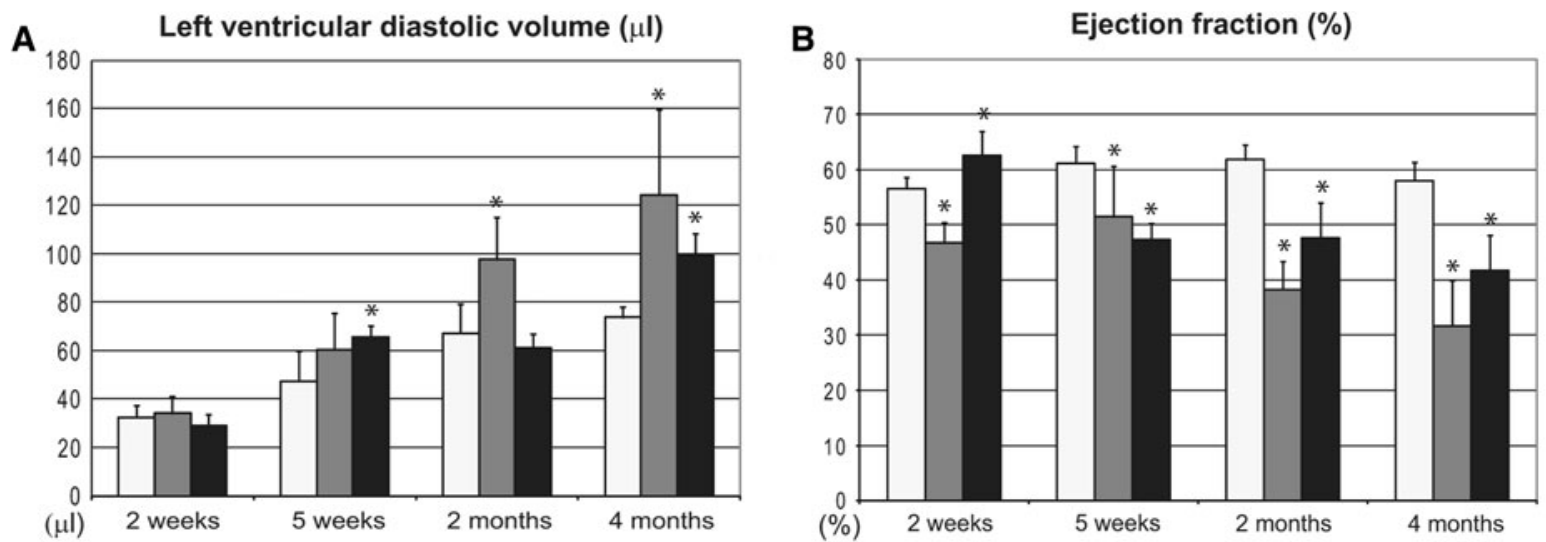

\section{C control}

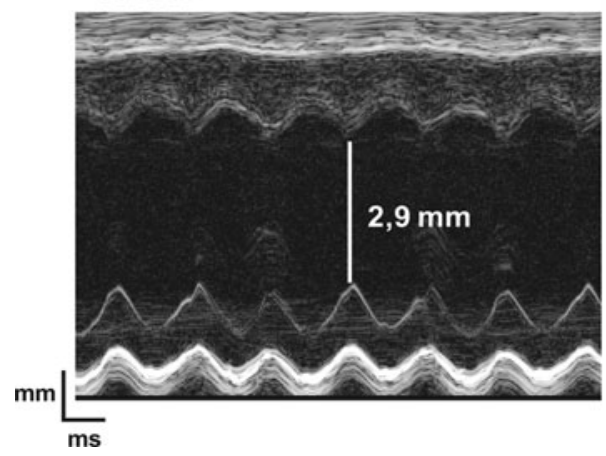

b-catenin $\Delta \mathrm{ex} 3$

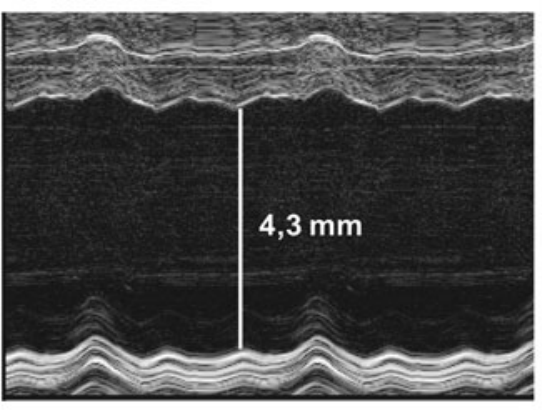

MLP KO

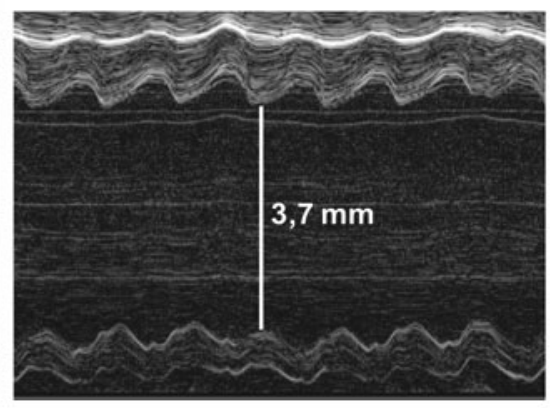

Fig. 2 Echocardiography of DCM models. a Left ventricular diastolic volume measurements confirming the DCM phenotype in MLP-KO (black) and more severe in $\beta$-catenin $\mathrm{c} \Delta \mathrm{ex} 3$ animals (gray) compared to controls (white). b Ejection fraction of control (white), $\beta$-catenin $\mathrm{c} \Delta \mathrm{ex} 3$ (gray) and MLP-KO (black) mice demonstrating the continuous decrease in heart function during progression of the disease. Error bars represent standard deviation, $N \geq 6$ for each subgroup. Asterisks mean significant differences compared to control groups. c M-mode echocardiographic tracings in control (left), $\beta$-catenin $\mathrm{c} \Delta \operatorname{ex} 3$ mice (center) and MLP-KO (right) at the age of 4 months. Left ventricular dimensions are indicated by white lines 

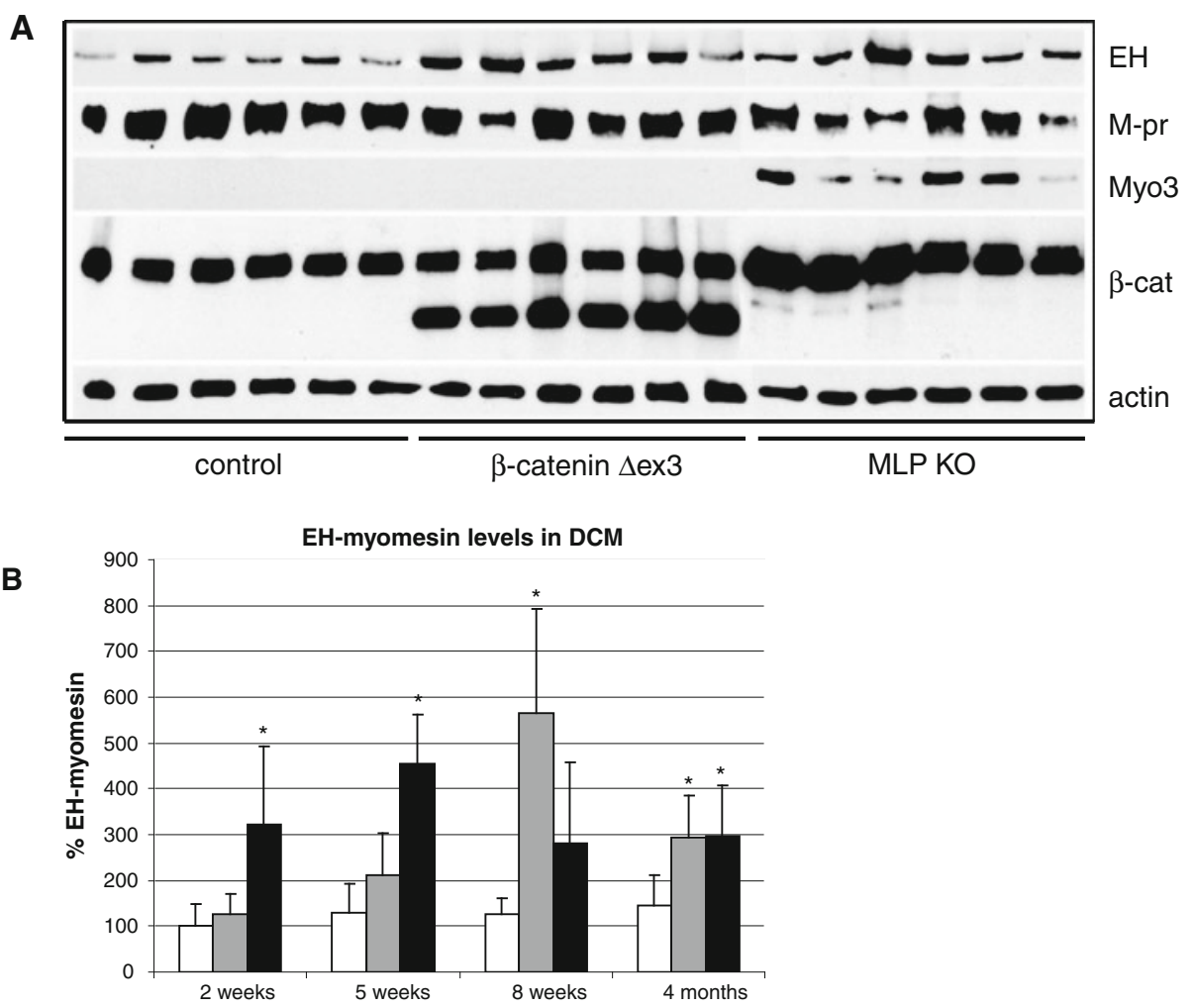

Fig. 3 Expression of myomesin proteins during development of dilated cardiomyopathy. a Immunoblot analysis of mouse heart protein extracts of control, $\beta$-catenin $\mathrm{c} \Delta \mathrm{ex} 3$ mice and MLP-KO mice (age 2 months). EH-myomesin (EH) is accumulated in several animals suffering from DCM with variability between individual mice. A slight down-regulation of $\mathrm{M}$-protein is detectable in the $\beta$ catenin $\mathrm{c} \Delta \mathrm{ex} 3$ mice, which is more pronounced in the MLP-KO mice at the age of 2 months (M-pr). Myomesin-3 up-regulation is detectable only in the MLP-KO mice (Myo3). $\beta$-Catenin ( $\beta$-cat) is accumulated in both mouse models, with the $\beta$-catenin $\mathrm{c} \Delta \mathrm{ex} 3$ mice showing expression of the truncated form (lower bands) in addition to the normal protein (upper bands). b Quantification of EH-myomesin levels during disease development shows an accumulation already at
2 weeks in the MLP-KO mice (black columns). In the $\beta$-catenin $\mathrm{c} \Delta \mathrm{ex} 3$ model (gray columns) a significant up-regulation of this isoform is detectable at the age of 8 weeks. At 4 months, both DCM models show an accumulation of EH-myomesin. Expression levels are normalized on sarcomeric actin levels and compared to control mice. Error bars represent standard deviation, $N \geq 6$ for each subgroup. Asterisks mean significant differences compared to control groups. $P$ values compared to control were as follows: 2 weeks $(\beta$ catenin $\mathrm{c} \Delta \mathrm{ex} 3, P=0.163$; MLP KO, $P=0.007), 5$ weeks $(\beta$-catenin $\mathrm{c} \Delta \mathrm{ex} 3, P=0.089$; MLP KO, $P=0.001), 2$ months $(\beta$-catenin $\mathrm{c} \Delta \mathrm{ex} 3$, $P=0.016 ;$ MLP KO, $P=0.067), 4$ months $(\beta$-catenin $\mathrm{c} \Delta \mathrm{ex} 3$, $P=0.016 ;$ MLP KO, $P=0.041) . w$ weeks, $m$ months

sin-3 can be detected only in the MLP-KO mice (Fig. 3a, Myo3), which is consistent with the RT-PCR analysis (Figure $\mathrm{S} 1$ ). In addition, $\beta$-catenin is clearly accumulated in both mouse models (Fig. 3a, $\beta$-cat), in accordance with previous studies, reporting the up-regulation of adherens junction protein components in dilated heart [31]. To confirm that the up-regulation of EH-myomesin in the heart is a general phenomenon of mouse DCM models, two additional models have been analyzed by Western blot (Supplementary Table S2). In addition, a non-genetic mouse model for heart failure (ischemic cardiomyopathy due to chronic left anterior descending artery ligation [27]) was analyzed and showed up-regulation of EH-myomesin in the scar region of the myocardial infarct, where the ventricular wall is very thin (Supplementary Figure S2). 


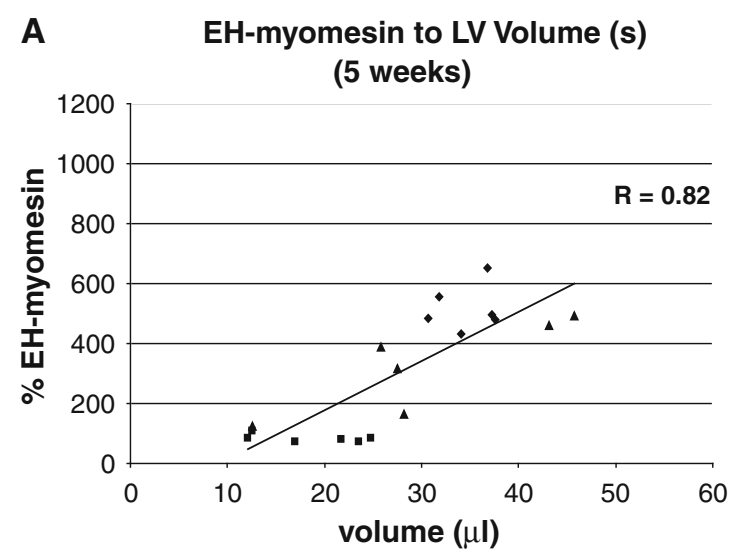

C

\begin{tabular}{|l|r|r|r|}
\hline Correlation coefficients & \multicolumn{1}{|c|}{$5 \mathrm{w}$} & $2 \mathrm{~m}$ & \multicolumn{1}{|c|}{$4 \mathrm{~m}$} \\
\hline & & & \\
\hline LV Volume (s) & 0.82 & 0.73 & 0.45 \\
\hline LVID (s) & 0.81 & 0.7 & 0.47 \\
\hline EF\% & -0.86 & -0.46 & -0.42 \\
\hline
\end{tabular}

Fig. 4 Comparison of EH-myomesin expression with heart parameters. a Left ventricular (LV) volume in systole measured by echocardiography at the age of 5 weeks correlates with EH-myomesin expression in MLP-KO (oblique squares, $N=6$ ) and $\beta$-catenin $\mathrm{c} \Delta \mathrm{ex} 3$ mice (triangles, $N=6$ ). The $\beta$-catenin $\mathrm{c} \Delta \mathrm{ex} 3$ transgenic animals show a relatively wide distribution in volume, whereas the MLP-KO mice have a significant dilation including up-regulation of EH-myomesin expression already at this age. The strong correlation between $\mathrm{LV}$ volume and $\mathrm{EH}$-myomesin accumulation is reflected by a correlation coefficient of $R=0.82$. Control mice are shown as squares $(N=6)$. b At the age of 5 weeks, the controls (squares) and

Accumulation of EH-myomesin correlates with dilation and impairment of heart function

To analyze the potential of EH-myomesin up-regulation as a marker for DCM and to investigate its role in disease development, protein levels of this isoform were compared to cardiac parameters measured by echocardiography. Already at the age of 5 weeks, there was a strong correlation between the left ventricular (LV) systolic volume and EH-myomesin accumulation (correlation coefficient $R=0.82$, Fig. 4a). At this age, all MLP-KO mice suffer from a significant dilation including EH-myomesin upregulation, whereas the $\beta$-catenin $\mathrm{c} \Delta \mathrm{ex} 3$ animals show a relatively wide variation in LV systolic volume. Furthermore, the ejection fraction was measured and compared with the accumulation of EH-myomesin (Fig. 4b). At the age of 5 weeks, two out of six $\beta$-catenin $c \Delta$ ex 3 animals still had a normal heart function with an ejection fraction around $60 \%$ and normal levels of the EH-myomesin isoform. However, four out of six of the $\beta$-catenin $\mathrm{c} \Delta \mathrm{ex} 3$ animals had a significantly reduced ejection fraction compared to controls and showed up-regulation of this protein. The coefficient $R=-0.86$ highlighted the strong negative correlation between ejection fraction and
\% Ejection Fraction to EH-myomesin (5 weeks)

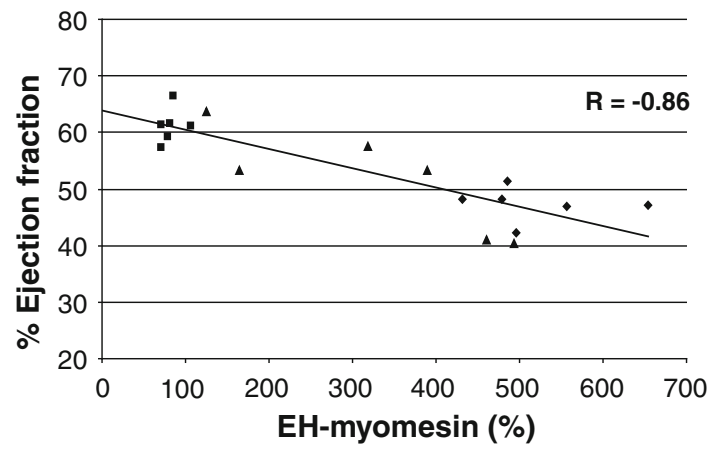

some of the $\beta$-catenin $\mathrm{c} \Delta \mathrm{ex} 3$ animals (triangles) have a normal ejection fraction (about 60\%) including normal levels of $\mathrm{EH}$ myomesin. Animals with a clearly reduced ejection fraction have accumulated this protein significantly. The strong negative correlation is reflected by a correlation coefficient $R=-0.86$. c Table showing the correlation coefficients for the relations between EH-myomesin protein levels and LV systolic volume (LV Volume, s), LV systolic internal diameter (LVID, s) or \% ejection fraction (EF\%). The strongest correlations were found at the age of 5 weeks. $5 w 5$ weeks, $2 m 2$ months, $4 m 4$ months

EH-myomesin accumulation. The correlation coefficients between EH-myomesin and the cardiac parameters LV systolic volume, LV systolic internal diameter and ejection fraction were compared at different stages of the disease (Fig. 4c). The strongest correlations were found at the age of 5 weeks and were slightly reduced at later stages of the disease.

EH-myomesin is up-regulated in cardiomyocytes of mouse DCM models in a cell-specific fashion

The expression of EH-myomesin and M-protein was analyzed at the cellular level by immunofluorescence analysis of mouse heart cryosections (age 4 months, Fig. 5). In dilated hearts, these proteins changed their expression in a cell-specific manner: EH-myomesin is accumulated in both DCM models with certain heterogeneity, whereas M-protein is slightly down-regulated.

The $\beta$-catenin $\mathrm{c} \Delta \mathrm{ex} 3$ mouse progressively develops severe DCM and dies at the latest of 6 months. To evaluate the expression of M-band components at the end-stage of DCM in more detail, $\beta$-catenin $\mathrm{c} \Delta \mathrm{ex} 3$ mice were analyzed at the age of 5 months and compared to MLP-KO and control mice (Fig. 6). In these hearts, 
Fig. 5 Heterogeneous accumulation of EH-myomesin in cardiomyocytes of mouse DCM models. Cryosections of mouse heart ventricles of control $(\mathbf{a}, \mathbf{d}, \mathbf{g}, \mathbf{k}, \mathbf{n}), \beta$-catenin $\mathrm{c} \Delta \operatorname{ex} 3(\mathbf{b}, \mathbf{e}, \mathbf{h}, \mathbf{l}, \mathbf{o})$ and MLP $\mathrm{KO}(\mathbf{c}, \mathbf{f}, \mathbf{i}, \mathbf{m}, \mathbf{p})$ mice at the age of 4 months quadruple-stained with antibodies against M-protein (d-f; green in overlays), EH-myomesin (g-i; blue in overlays), DAPI (k-m; red in overlays) and $\mathrm{N}$-cadherin (n-p). A downregulation of M-protein is apparent in single cardiomyocytes of the $\beta$-catenin $\mathrm{c} \Delta \mathrm{ex} 3$ transgenic animals. In contrast, M-protein is relatively homogenously expressed in MLP KO (f) and control mice (d). EH-myomesin is accumulated in both DCM models (h, $\mathbf{i}$; blue in $\mathbf{b}, \mathbf{c}$ ) with certain heterogeneity. In the $\beta$-catenin $\mathrm{c} \Delta \mathrm{ex} 3$ transgenic animals, the same cardiomyocytes, which show an up-regulation of EH-myomesin (h), have reduced levels of M-protein (e), leading to a more embryonic-like phenotype. A big accumulation of nuclei can be detected in the hearts of $\beta$-catenin $\mathrm{c} \Delta \mathrm{ex} 3$ mice $(\mathbf{l}$, red in overlay), including fibrosis (regions without M-band staining) and some hypertrophied nuclei. The accumulation of the intercalated disk component $\mathrm{N}$-cadherin $(\mathbf{n}-\mathbf{p})$ is visible in both DCM mouse models. Scale bar $100 \mu \mathrm{m}$
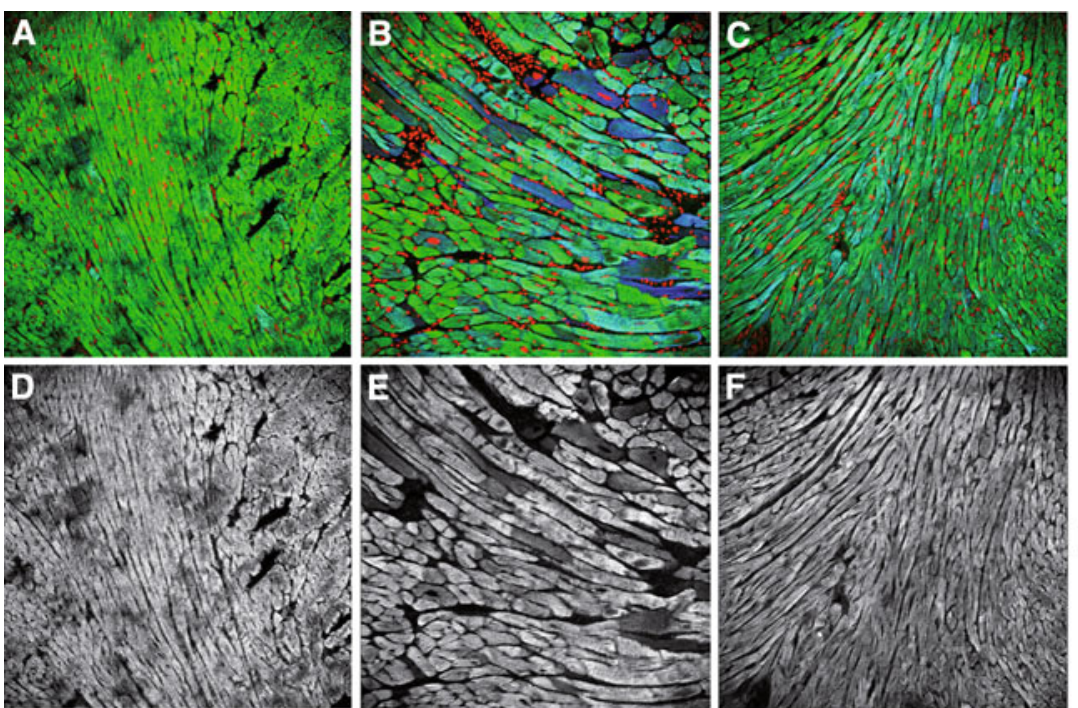

M-protein
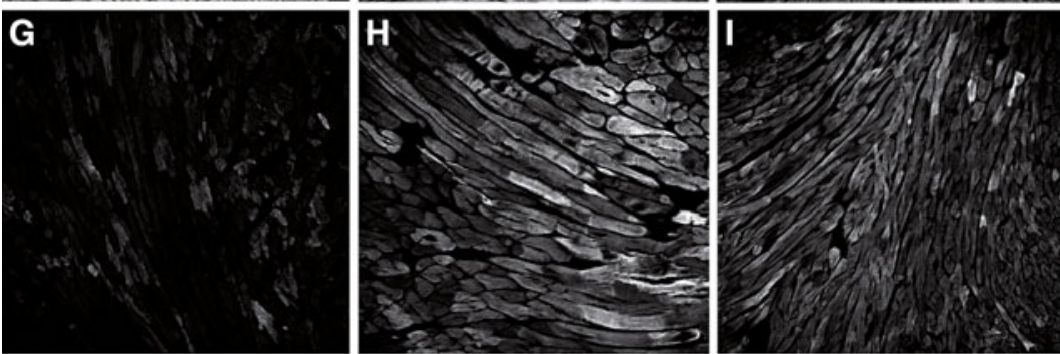

EH-myomesin
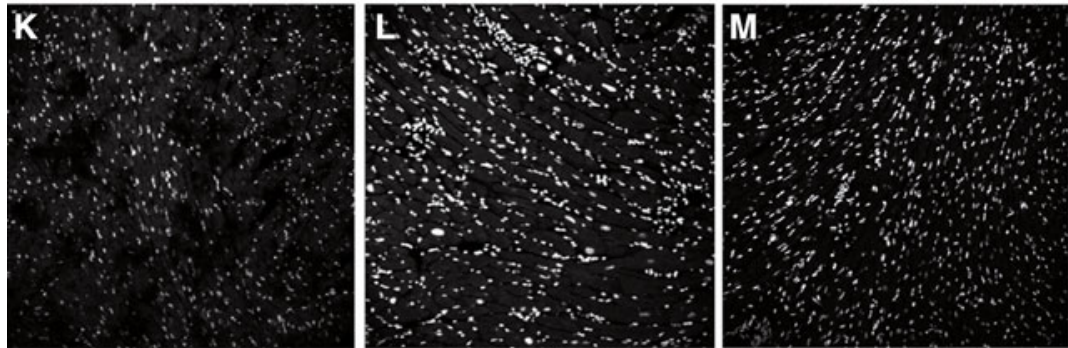

DAPI
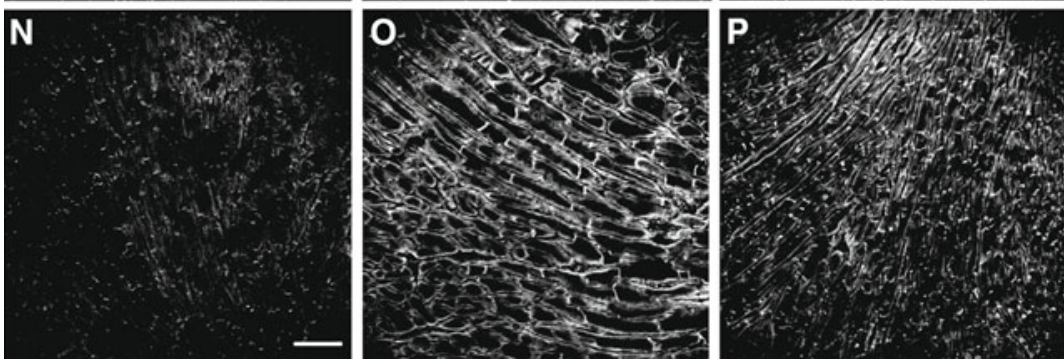

EH-myomesin expression showed considerable heterogeneity with a complete switch to an embryonic phenotype in some cardiomyocytes (Fig. 6, asterisk in b, e, h). M-protein was significantly down-regulated in both DCM models compared to controls (Fig. 6d-f). This downregulation is rather homogenous in the MLP-KO, whereas in the $\beta$-catenin $\mathrm{c} \Delta \mathrm{ex} 3$ animals it was patchy in respect to single cardiomyocytes. $\beta$-Catenin (Fig. $6 \mathrm{k}-\mathrm{m}$, red in a-c) was up-regulated in both DCM models, as described [12].
Up-regulation of EH-myomesin in human DCM patients

To check the expression of the myomesin isoforms in the heart of humans suffering from cardiomyopathy, RT-qPCR analysis was carried out using total RNA isolated from heart biopsies of patients suffering from DCM and compared to non-dilated control hearts. Myomesin was expressed evenly (Figure S3), whereas the EH-myomesin isoform was significantly up-regulated in the hearts of most 
Fig. 6 Expression of M-band components at the end-stage of DCM. Cryosections of mouse heart ventricles of control $(\mathbf{a}, \mathbf{d}$, $\mathbf{g}, \mathbf{k}), \beta$-catenin $\mathrm{c} \Delta \operatorname{ex} 3(\mathbf{b}, \mathbf{e}, \mathbf{h}$, l) and MLP-KO (c, f, i, m) mice at the age of 5 months triplestained with antibodies against M-protein (d-f; green in overlays), EH-myomesin (g-i; blue in overlays), and $\beta$-catenin (k-m; red in overlays). M-protein is homogenously expressed in control mice (d), whereas in $\beta$-catenin $\mathrm{c} \Delta \mathrm{ex} 3$ (e) and MLP-KO (f) transgenic animals it is significantly downregulated. This down-regulation is homogenous in the MLP-KO, whereas in the $\beta$-catenin $\mathrm{c} \Delta \mathrm{ex} 3$ animals it is extremely heterogeneous. EH-myomesin is up-regulated extremely heterogeneously in the $\beta$-catenin $\mathrm{c} \Delta \mathrm{ex} 3$ transgenic animals. Some single cardiomyocytes show a switch to an embryonic phenotype of M-bands, with higher level of EH-myomesin expression and very low M-protein expression level (asterisk in $\mathbf{e}, \mathbf{h}$ ).

$\beta$-Catenin is strongly accumulated in both DCM models $(\mathbf{l}, \mathbf{m}$; red in $\mathbf{b}, \mathbf{c})$. Scale bar $20 \mu \mathrm{m}$
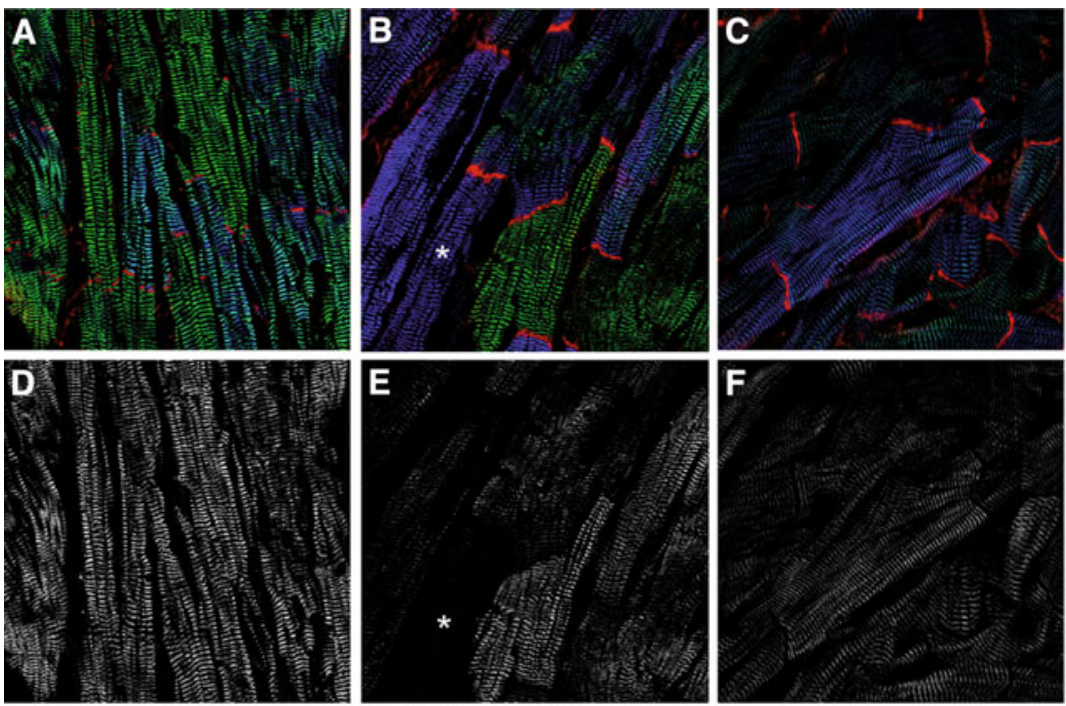

M-protein
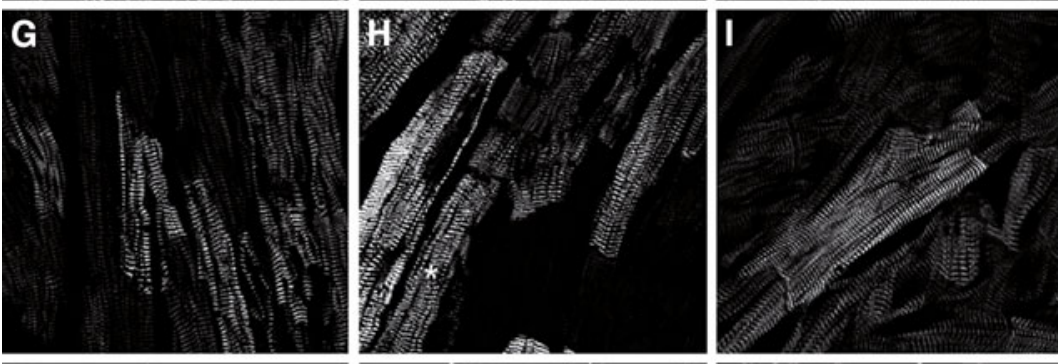

EH-myomesin
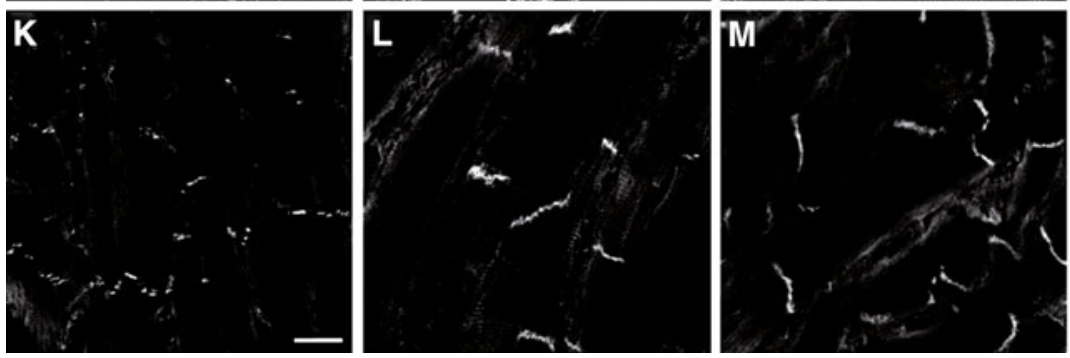

$\beta$-catenin patients suffering from DCM compared to non-dilated controls and to patients suffering from HCM, with considerable variability in the expression levels (Fig. 7, Fig. S4). No significant accumulation of EH-myomesin could be detected in hearts of patients treated by a LVAD. In DCM patients without LVAD, the up-regulation of EHmyomesin was 41 times compared to controls. The correlation coefficient between \% ejection fraction and the expression level of EH-myomesin was $R=-0.64$, confirming the correlation in the transgenic DCM mouse models. In all patients with an ejection fraction below $20 \%$, EH-myomesin levels were up-regulated at least 10 times compared to control patients. We have found no indication that medication affected the expression of EH-myomesin.

Furthermore, stainings of cryosections of human hearts were performed to confirm the re-expression of $\mathrm{EH}$ myomesin in human DCM patients (Fig. 8, right) compared to a healthy control (Fig. 8, left). The sections were triple stained with antibodies against M-protein, EH-myomesin, and $\beta$-catenin. M-protein was homogenously expressed in both hearts, whereas EH-myomesin was re-expressed in single cardiomyocytes of the DCM patients. These results were consistent with the data obtained from mouse DCM models.

Myomesin-3 is expressed in human skeletal muscle and adult heart

To analyze whether the myomesin genes were expressed in a tissue-specific manner also in human, RT-PCR analysis was performed on total RNA isolated from different human tissues (Figure S5). The muscle tissue samples were tested with primers specific for different myomesins (Table S1). Myomesin was detectable in all types of human-striated muscle, whereas EH-myomesin was found in the embryonic heart. M-protein was highly expressed in embryonic 


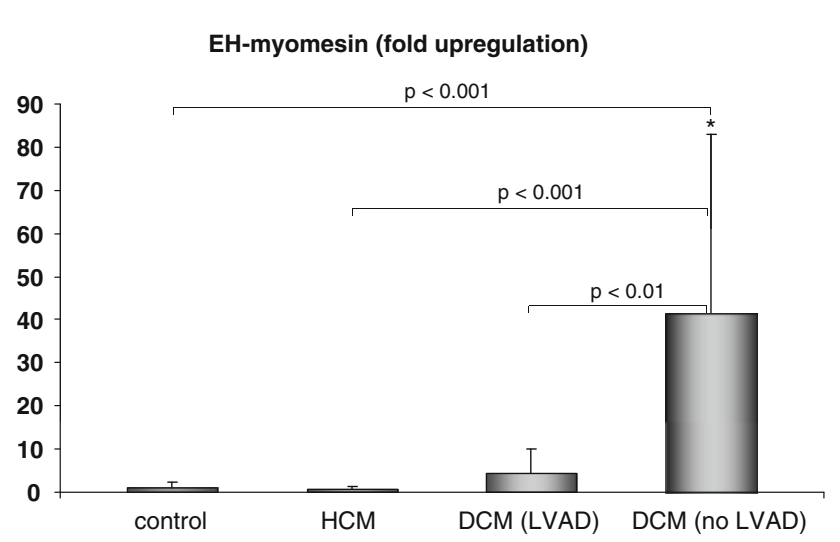

Fig. 7 EH-myomesin is re-expressed in human patients suffering from DCM. RT-qPCR analysis of human patients suffering from $\mathrm{DCM}$ or HCM using primers specific for $\mathrm{EH}-m y o m e s i n$. This isoform is massively up-regulated (41 times) in the hearts of patients suffering from DCM (right column, $N=10$ ) compared to non-dilated control hearts $(N=5)$ and hearts of patients suffering from HCM $(N=7)$. DCM patients under treatment with a left ventricular assist device (LVAD, $N=3$ ) show no significant re-expression of the EHmyomesin isoform. Sarcomeric $\alpha$-actinin was used for normalization. $H C M$ hypertrophic cardiomyopathy, DCM dilated cardiomyopathy, LVAD left ventricular assist device. Error bars represent standard deviation. Asterisk means significant difference compared to the other tested groups

skeletal muscle and adult heart of human. In contrast to mouse, myomesin-3 was detectable not only in skeletal muscle, but also in the adult human myocardium.

\section{Discussion}

Previous studies described the M-band as a dynamic element of the sarcomeric cytoskeleton which adapts to the contractile regime of a particular muscle by varying the type and number of different myomesin molecules crosslinking the thick filaments [3]. Here, we characterize the M-band protein composition in mouse and human heart, in both healthy and pathological situations. We show that expression patterns of myomesins correlate with the physiological parameters of the heart muscle, and vary depending on species, developmental stage or type of cardiomyopathy (Tables 3, 4).

The M-band protein composition is identical in embryonic heart of mouse and human and is restricted to the EH-myomesin isoform. However, this isoform is downregulated around birth and the adult hearts show distinct expression patterns of myomesins (Table 3). Human myocardium accumulates much more myomesin-3 compared to mouse heart. Thus, the M-band composition of mouse heart resembles fast skeletal fibers, while that in human heart is more close to intermediate speed fibers [36]. This can be explained by different physiological demands to the M-bands. The mouse heart beats much faster than the human one, and the mouse heart myosin produces much higher contraction speed [7]. Both parameters probably necessitate the presence of a "faster" M-band in mouse myocardium. Our observations showed the limitations in direct applicability of results obtained from mouse models for the human heart. The differences in physiological characteristics and in the cytoskeletal design between mouse and human hearts should always be taken into account by any prediction.

Our experiments showed an accumulation of EHmyomesin in both mouse models of DCM (MLP-KO and $\beta$-catenin $\mathrm{c} \Delta \mathrm{ex} 3$ ), which correlated well with the decrease of ejection fraction at the early stage of disease. This suggests EH-myomesin as an early marker of DCM. In addition to EH-myomesin up-regulation, we found that some DCM mouse models (e.g. MLP-KO mice) up-regulated myomesin-3 expression, which might represent a fine-tuning of the M-band to specific biomechanical alterations. As discussed above, the adult human heart has a different M-band composition compared to mouse. However, the up-regulation of EH-myomesin was a constant characteristic also of DCM in human heart, irrespective of the cause of the disease. We found that expression of EHmyomesin is dramatically up-regulated (41-fold, $P<0.001$ ) in the DCM group compared to the control and HCM groups. The up-regulation of EH-myomesin was much lower in DCM hearts supported by a LVAD.

The up-regulation of EH-myomesin in DCM is consistent with the reported re-expression of fetal isoforms of sarcomeric proteins in the dilated heart [10]. Accordingly, the appearance of the myomesin isoform containing the additional elastic EH-fragment matches the up-regulation of compliant titin isoforms in human DCM [26, 29], suggestive of a correlative adaptation of both cytoskeletal structures in this pathological situation.

What might be the reason for such a remodeling of the sarcomere cytoskeleton? We propose that it is a general adaptation to the altered contractile mechanics of the sarcomere in the dilated heart. Indeed, our observations show that up-regulation of EH-myomesin is universal for all tested DCM hearts, irrespectively of species and regardless to the cause of the disease. Also, the increase of the EHmyomesin expression correlates well with the decrease of the heart pumping function and correspondingly to the increase of volume overload in the dilated heart. Previously, EH-myomesin expression was reported in fibers working in the eccentric contraction regime in mouse skeletal [4] and rat extraocular muscles [39]. The sarcomere in the dilated heart has to contract in overstretched conditions as well, requiring the switch to a "fuzzy sarcomere" design, which is more stable in eccentric conditions [2]. The application of LVAD leads to a decreased load of the contracting sarcomere, which correlates with 
Fig. 8 EH-myomesin is upregulated in the heart of human DCM patients in cell-specific fashion. Confocal images of cryosections of human hearts of control $(\mathbf{a}, \mathbf{c}, \mathbf{e}, \mathbf{g})$ and a DCM patient (left ventricle; $\mathbf{b}, \mathbf{d}, \mathbf{f}, \mathbf{h}$ ) triple-stained with antibodies against M-protein (c, $\mathbf{d}$; green in overlays), EH-myomesin (e, f; blue in overlays), and with $\beta$-catenin (g, $\mathbf{h}$; red in overlay). M-protein is homogenously expressed in both hearts $(\mathbf{c}, \mathbf{d})$, whereas EH-myomesin is upregulated in the DCM patient in a cell-specific manner. Scale bar $10 \mu \mathrm{m}$
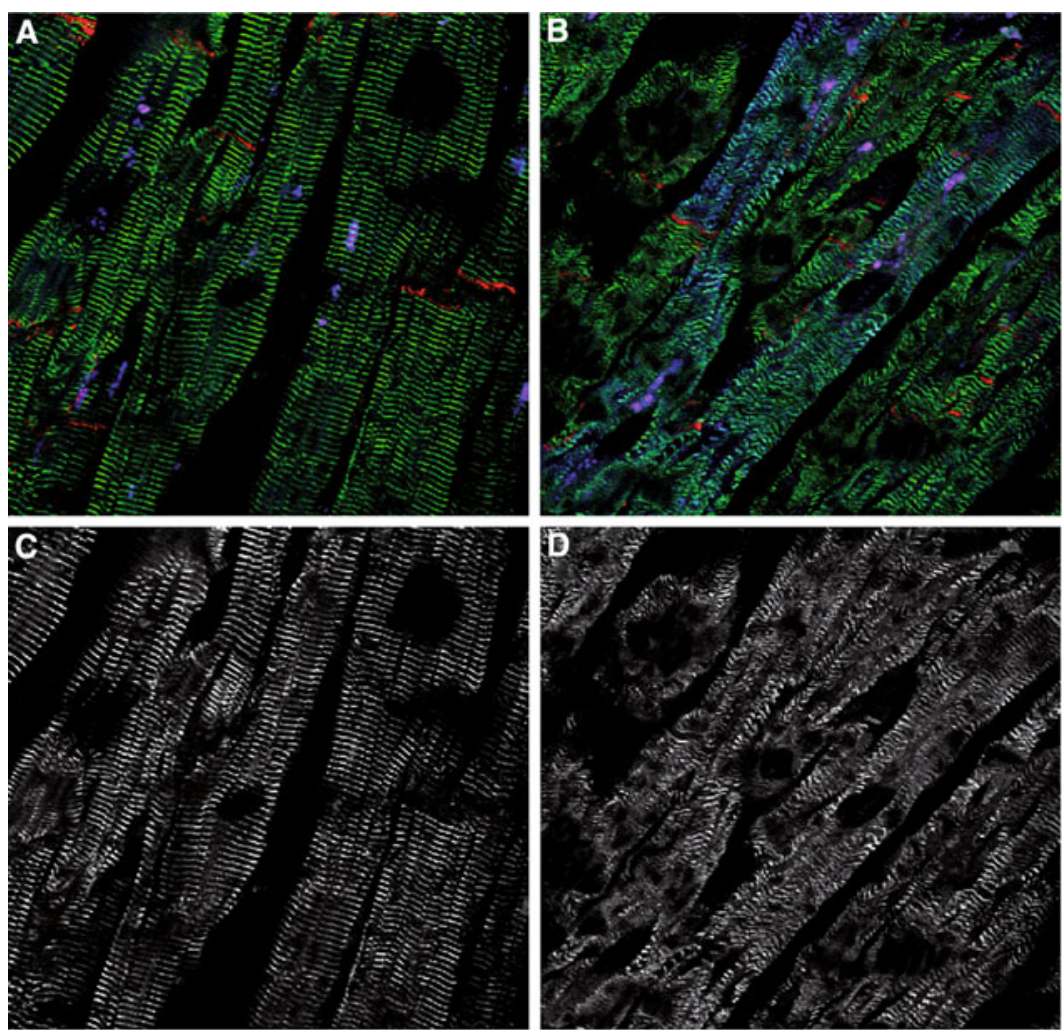

M-protein
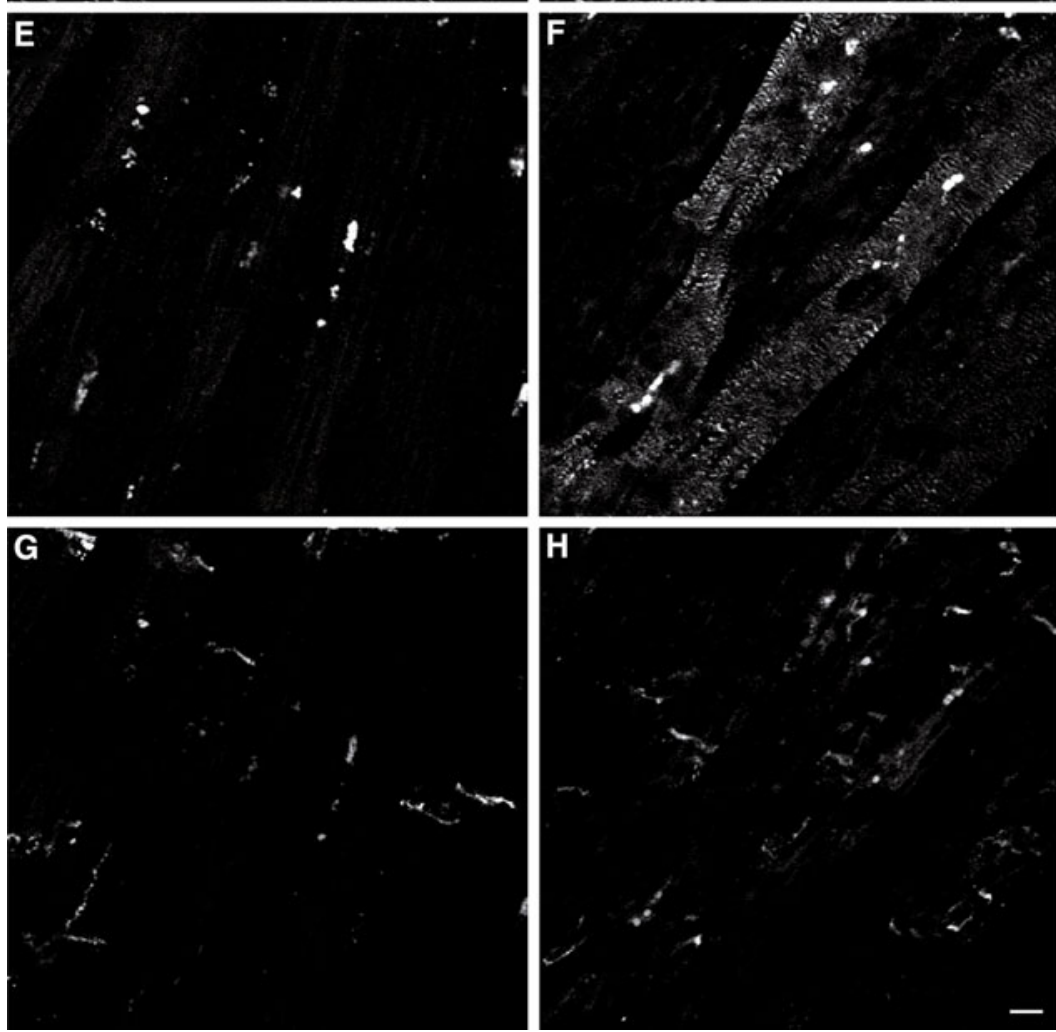

EH-myomesin

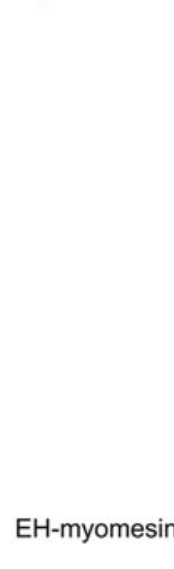

$\beta$-catenin much lower levels of EH-myomesin in the LVAD supported hearts.

The remodeling to a more embryonic type of cytoskeleton might also be an adaptive response to calcium signaling defects in the failing heart. Indeed, the failing human heart shows slower relaxation kinetics caused by delayed $\mathrm{Ca}^{2+}$ re-uptake [8] due to reduced SERCA function, enhanced NCX function, and greater $\mathrm{Ca}^{2+}$ leak from the 
Table 3 Summary of expression data of myomesin proteins in the heart of mouse and human

\begin{tabular}{lllllll}
\hline & \multicolumn{2}{l}{ Mouse heart } & & \multicolumn{2}{l}{ Human heart } \\
\cline { 2 - 3 } \cline { 5 - 6 } \cline { 5 - 6 } & Embryonic & Adult & & Embryonic & Adult \\
\hline EH-myomesin & + & Low level & + & Low level \\
M-protein & - & + & & - & + \\
Myomesin-3 & - & - & & - & +
\end{tabular}

While in embryonic development EH-myomesin is the main M-band component in the heart of both mouse and human, the adult hearts show species-specific expression patterns of myomesins. The human myocardium is characterized by higher levels of myomesin-3

Table 4 Summary of alterations in expression of myomesins in DCM in mouse and human

\begin{tabular}{llll}
\hline & $\mathrm{c} \Delta \mathrm{ex} 3 \beta$-cat mice & MLP-KO mice & Human DCM \\
\hline EH-myomesin & $\uparrow$ & $\uparrow$ & $\uparrow$ \\
M-protein & $\downarrow$ & $\downarrow$ & - \\
Myomesin-3 & - & $\uparrow$ & - \\
\hline
\end{tabular}

The up-regulation of EH-myomesin is the main marker for DCM in both mouse and human heart. Changes between M-protein and myomesin-3 expression might discriminate between different DCM mouse models

$\uparrow$ up-regulation, $\downarrow$ slight down-regulation, -: no alteration detectable

sarcoplasmic reticulum [6]. In the embryonic heart, the $\mathrm{Ca}^{2+}$ re-uptake is compromised by immature excitationcontraction coupling [11]. The LVAD support improves the contractility of the failing heart and shortens the rate of the $\mathrm{Ca}^{2+}$ decay to the level of non-failing heart [8]. This correlates with our finding that EH-myomesin expression in LVAD supported hearts does not differ significantly from the non-dilated control hearts.

We have found that the M-band composition changes in a cell-autonomous fashion in the failing heart. In the heart of $\beta$-catenin $\mathrm{c} \Delta \mathrm{ex} 3$ mice, some cardiomyocytes switch completely to the embryonic M-band phenotype by upregulating EH-myomesin and down-regulating M-protein, whereas others keep the phenotype of adult cardiomyocytes with high levels of M-protein and very low levels of EH-myomesin. The down-regulation of M-protein is not detectable in the human DCM hearts, but EH-myomesin is also up-regulated in a cell-specific manner. We intend that increased myocardial strain in dilated heart might provoke the up-regulation of EH-myomesin and "patchy", cellspecific expression pattern might be caused by a different mechanical burden on certain myocytes. This suggestion is supported by the observation that a strong up-regulation of EH-myomesin is observed in the scar region of the heart remodeled after myocardial infarction, as the ventricular wall is very thin in the scar region and the slim layer of remaining myocytes is subjected to huge contractile stress.
This is a very important observation, because all molecular alterations found by previous studies in the diseased myocardium were averaged values for the whole heart and did not consider the divergence between individual cardiomyocytes. We, therefore, hypothesize that M-band alterations might be part of a general adaptation of the sarcomeric cytoskeleton to unfavorable working conditions in the failing heart, and might also affect the mechanical properties of the cardiomyocytes. The progressive cell-tocell heterogeneity through the myocardial wall would impair the force transmission and might have important implications for the mechanism of cardiac failure. Computer models showed that occurrence of mechanical non-uniformities in myocardial muscle might lead to spontaneous $\mathrm{Ca}^{2+}$ release from sarcoplasmic reticulum and initiate arrhythmogenic waves [37]. Thus, the cytoskeletal alterations by DCM, initially driven by a compensatory mechanism, may eventually become maladaptive with disease progression. However, further studies are needed to clarify the role of cytoskeletal non-uniformities in the development of arrhythmias in the failing heart.

Here, we present for the first time that EH-myomesin, the dominant myomesin isoform in the embryonic heart, is up-regulated in DCM. Since we have previously shown that this myomesin isoform is associated with a higher degree of M-band elasticity [35], this finding might give new insights into the understanding of progressive ventricular dilation on a structural level. Furthermore, the up-regulation of EH-myomesin at early stages of the disease and its correlation to the impairment of ventricular function may be used for a better characterization of DCM in human patients.

Acknowledgments This work was funded by grants from Swiss Foundation for Research on Muscle Diseases, Wolfermann-Nägeli Foundation and Roche Research Foundation to I.A. R.S. was supported by a research grant from the Medical Faculty of the University of Zurich. Work in the laboratory of E.E. is supported by the MRC. The work performed by the Cardiovascular Assessment Facility at the University of Lausanne is cordially acknowledged. We specially thank U. Steckholzer-Schärer for the technical assistance and J.-C. Perriard for his continuous support.

Open Access This article is distributed under the terms of the Creative Commons Attribution Noncommercial License which permits any noncommercial use, distribution, and reproduction in any medium, provided the original author(s) and source are credited.

\section{References}

1. Agarkova I, Auerbach D, Ehler E, Perriard JC (2000) A novel marker for vertebrate embryonic heart, the EH-myomesin isoform. J Biol Chem 275:10256-10264 
2. Agarkova I, Ehler E, Lange S, Schoenauer R, Perriard JC (2003) M-band: a safeguard for sarcomere stability? J Muscle Res Cell Motil 24:191-203

3. Agarkova I, Perriard JC (2005) The M-band: an elastic web that crosslinks thick filaments in the center of the sarcomere. Trends Cell Biol 15:477-485

4. Agarkova I, Schoenauer R, Ehler E, Carlsson L, Carlsson E, Thornell LE, Perriard JC (2004) The molecular composition of the sarcomeric M-band correlates with muscle fiber type. Eur J Cell Biol 83:193-204

5. Arber S, Hunter JJ, Ross JJ, Hongo M, Sansig G, Borg J, Perriard JC, Chien KR, Caroni P (1997) MLP-deficient mice exhibit a disruption of cardiac cytoarchitectural organization, dilated cardiomyopathy, and heart failure. Cell 88:393-403

6. Bers DM, Despa S, Bossuyt J (2006) Regulation of $\mathrm{Ca}^{2+}$ and $\mathrm{Na}^{+}$ in normal and failing cardiac myocytes. Ann N Y Acad Sci 1080:165-177

7. Chandra M, Tschirgi ML, Ford SJ, Slinker BK, Campbell KB (2007) Interaction between myosin heavy chain and troponin isoforms modulate cardiac myofiber contractile dynamics. Am J Physiol Regul Integr Comp Physiol 293:1595-1607

8. Chaudhary KW, Rossman EI, Piacentino V 3rd, Kenessey A, Weber C, Gaughan JP, Ojamaa K, Klein I, Bers DM, Houser SR, Margulies KB (2004) Altered myocardial $\mathrm{Ca}^{2+}$ cycling after left ventricular assist device support in the failing human heart. J Am Coll Cardiol 44:837-845

9. Chen J, Kubalak SW, Chien KR (1998) Ventricular musclerestricted targeting of the RXRalpha gene reveals a non-cellautonomous requirement in cardiac chamber morphogenesis. Development 125:1943-1949

10. Chien KR (1999) Stress pathways and heart failure. Cell 98:555-558

11. Creazzo TL, Burch J, Godt RE (2004) Calcium buffering and excitation-contraction coupling in developing avian myocardium. Biophys J 86:966-977

12. Ehler E, Horowits R, Zuppinger C, Price RL, Perriard E, Leu M, Caroni P, Sussman M, Eppenberger HM, Perriard JC (2001) Alterations at the intercalated disk associated with the absence of muscle LIM protein. J Cell Biol 153:763-772

13. Elliott P, Andersson B, Arbustini E, Bilinska Z, Cecchi F, Charron P, Dubourg O, Kuhl U, Maisch B, McKenna WJ, Monserrat L, Pankuweit S, Rapezzi C, Seferovic P, Tavazzi L, Keren A (2008) Classification of the cardiomyopathies: a position statement from the European Society Of Cardiology Working Group on Myocardial and Pericardial Diseases. Eur Heart J 29:270-276

14. Fatkin D, Otway R, Richmond Z (2010) Genetics of dilated cardiomyopathy. Heart Fail Clin 6:129-140

15. Grove BK, Cerny L, Perriard JC, Eppenberger HM (1985) Myomesin and M-protein: expression of two M-band proteins in pectoral muscle and heart during development. J Cell Biol 101:1413-1421

16. Grove BK, Kurer V, Lehner C, Doetschman TC, Perriard JC, Eppenberger HM (1984) A new 185,000-Da skeletal muscle protein detected by monoclonal antibodies. J Cell Biol 98:518-524

17. Gupta P, Bilinska ZT, Sylvius N, Boudreau E, Veinot JP, Labib S, Bolongo PM, Hamza A, Jackson T, Ploski R, Walski M, Grzybowski J, Walczak E, Religa G, Fidzianska A, Tesson F (2010) Genetic and ultrastructural studies in dilated cardiomyopathy patients: a large deletion in the lamin A/C gene is associated with cardiomyocyte nuclear envelope disruption. Basic Res Cardiol 105:365-377

18. Harada N, Tamai Y, Ishikawa T, Sauer B, Takaku K, Oshima M, Taketo MM (1999) Intestinal polyposis in mice with a dominant stable mutation of the beta-catenin gene. EMBO J 18:5931-5942
19. Hirschy A, Croquelois A, Perriard E, Schoenauer R, Agarkova I, Hoerstrup SP, Taketo MM, Pedrazzini T, Perriard JC, Ehler E (2010) Stabilised beta-catenin in postnatal ventricular myocardium leads to dilated cardiomyopathy and premature death. Basic Res Cardiol 105:597-608

20. Kamisago M, Sharma SD, DePalma SR, Solomon S, Sharma P, McDonough B, Smoot L, Mullen MP, Woolf PK, Wigle ED, Seidman JG, Seidman CE (2000) Mutations in sarcomere protein genes as a cause of dilated cardiomyopathy. N Engl J Med 343:1688-1696

21. Kaya Z, Katus HA (2010) Role of autoimmunity in dilated cardiomyopathy. Basic Res Cardiol 105:7-8

22. Knoll R, Hoshijima M, Hoffman HM, Person V, LorenzenSchmidt I, Bang ML, Hayashi T, Shiga N, Yasukawa H, Schaper W, McKenna W, Yokoyama M, Schork NJ, Omens JH, McCulloch AD, Kimura A, Gregorio CC, Poller W, Schaper J, Schultheiss HP, Chien KR (2002) The cardiac mechanical stretch sensor machinery involves a $\mathrm{Z}$ disc complex that is defective in a subset of human dilated cardiomyopathy. Cell 111:943-955

23. Lange S, Himmel M, Auerbach D, Agarkova I, Hayess K, Fürst DO, Perriard JC, Ehler E (2005) Dimerisation of myomesin: implications for the structure of the sarcomeric M-band. J Mol Biol 345:289-298

24. Lange S, Xiang F, Yakovenko A, Vihola A, Hackman P, Rostkova E, Kristensen J, Brandmeier B, Franzen G, Hedberg B, Gunnarsson LG, Hughes SM, Marchand S, Sejersen T, Richard I, Edstrom L, Ehler E, Udd B, Gautel M (2005) The kinase domain of titin controls muscle gene expression and protein turnover. Science 308:1599-1603

25. Lee HY, Kleber M, Hari L, Brault V, Suter U, Taketo MM, Kemler R, Sommer L (2004) Instructive role of Wnt/beta-catenin in sensory fate specification in neural crest stem cells. Science 303:1020-1023

26. Makarenko I, Opitz CA, Leake MC, Neagoe C, Kulke M, Gwathmey JK, del Monte F, Hajjar RJ, Linke WA (2004) Passive stiffness changes caused by upregulation of compliant titin isoforms in human dilated cardiomyopathy hearts. Circ Res 95:708-716

27. Michael LH, Entman ML, Hartley CJ, Youker KA, Zhu J, Hall SR, Hawkins HK, Berens K, Ballantyne CM (1995) Myocardial ischemia and reperfusion: a murine model. Am $\mathrm{J}$ Physiol 269:2147-2154

28. Morimoto S (2008) Sarcomeric proteins and inherited cardiomyopathies. Cardiovasc Res 77:659-666

29. Nagueh SF, Shah G, Wu Y, Torre-Amione G, King NM, Lahmers S, Witt CC, Becker K, Labeit S, Granzier HL (2004) Altered titin expression, myocardial stiffness, and left ventricular function in patients with dilated cardiomyopathy. Circulation 110:155-162

30. Obermann WM, Gautel M, Weber K, Furst DO (1997) Molecular structure of the sarcomeric $M$ band: mapping of titin and myosin binding domains in myomesin and the identification of a potential regulatory phosphorylation site in myomesin. EMBO $\mathrm{J}$ $16: 211-220$

31. Perriard JC, Hirschy A, Ehler E (2003) Dilated cardiomyopathy. A disease of the intercalated disc? Trends Cardiovasc Med 13:30-38

32. Perrot A, Hussein S, Ruppert V, Schmidt HH, Wehnert MS, Duong NT, Posch MG, Panek A, Dietz R, Kindermann I, Bohm M, Michalewska-Wludarczyk A, Richter A, Maisch B, Pankuweit S, Ozcelik C (2009) Identification of mutational hot spots in LMNA encoding lamin A/C in patients with familial dilated cardiomyopathy. Basic Res Cardiol 104:90-99

33. Pfaffl MW (2001) A new mathematical model for relative quantification in real-time RT-PCR. Nucleic Acids Res 29:e45

34. Puchner EM, Alexandrovich A, Kho AL, Hensen U, Schafer LV, Brandmeier B, Grater F, Grubmuller H, Gaub HE, Gautel M 
(2008) Mechanoenzymatics of titin kinase. Proc Natl Acad Sci USA 105:13385-13390

35. Schoenauer R, Bertoncini P, Machaidze G, Aebi U, Perriard JC, Hegner M, Agarkova I (2005) Myomesin is a molecular spring with adaptable elasticity. J Mol Biol 349:367-379

36. Schoenauer R, Lange S, Hirschy A, Ehler E, Perriard JC, Agarkova I (2008) Myomesin 3, a novel structural component of the M-band in striated muscle. J Mol Biol 376:338-351

37. Ter Keurs HE, Shinozaki T, Zhang YM, Zhang ML, Wakayama Y, Sugai Y, Kagaya Y, Miura M, Boyden PA, Stuyvers BD, Landesberg A (2008) Sarcomere mechanics in uniform and nonuniform cardiac muscle: a link between pump function and arrhythmias. Prog Biophys Mol Biol 97:312-331

38. Voigt A, Bartel K, Egerer K, Trimpert C, Feist E, Gericke C, Kandolf R, Klingel K, Kuckelkorn U, Stangl K, Felix SB,
Baumann G, Kloetzel PM, Staudt A (2010) Humoral anti-proteasomal autoimmunity in dilated cardiomyopathy. Basic Res Cardiol 105:9-18

39. Wiesen MH, Bogdanovich S, Agarkova I, Perriard JC, Khurana TS (2007) Identification and characterization of layer-specific differences in extraocular muscle M-bands. Invest Ophthalmol Vis Sci 48:1119-1127

40. Will RD, Eden M, Just S, Hansen A, Eder A, Frank D, Kuhn C, Seeger TS, Oehl U, Wiemann S, Korn B, Koegl M, Rottbauer W, Eschenhagen T, Katus HA, Frey N (2010) Myomasp/LRRC39, a heart- and muscle-specific protein, is a novel component of the sarcomeric M-band and is involved in stretch sensing. Circ Res. doi:10.1161/CIRCRESAHA.110.222372 